\title{
The experiences of early career geriatricians throughout Europe during the COVID-19 pandemic
}

\author{
Vojtech Mezera ${ }^{1,2}(-)^{-}$Anne W. Ekdahl ${ }^{3} \cdot$ Dominic Bertschi ${ }^{4} \cdot$ Maria Bonnici $^{5,6,7} \cdot$ Rui Buzaco $^{8}$. \\ Santiago Cotobal Rodeles ${ }^{9} \cdot$ Kseniia Eruslanova $^{10} \cdot$ Lubov Matchekhina $^{10} \cdot$ Laura Monica Perez Bazan $^{11}$. \\ Itxaso Marin Epelde ${ }^{12} \cdot$ Marina Kotsani $^{13} \cdot$ Grazia Daniela Femminella $^{14} \cdot$ Meltem Koca $^{15} \cdot$ Marian Dejaeger $^{16,17}$
}

Received: 9 October 2021 / Accepted: 14 December 2021 / Published online: 29 January 2022

(c) The Author(s), under exclusive licence to European Geriatric Medicine Society 2021

\section{Key summary points}

Aim To assess the experiences of early career geriatricians during the COVID-19 pandemic.

Findings The respondents reported moderate levels of anxiety, work overload, and strong disruption in their work routine and private lives.

Message Many early career geriatricians throughout Europe were involved as frontline workers in the care of older adults with COVID-19, and experienced a major impact on their professional and private lives.

\begin{abstract}
The COVID-19 pandemic has severely affected older adults and brought about unprecedented challenges to geriatricians. We aimed to evaluate the experiences of early career geriatricians (residents or consultants with up to 10 years of experience) throughout Europe using an online survey. We obtained 721 responses. Most of the respondents were females (77.8\%) and residents in geriatric medicine $(54.6 \%)$. The majority $(91.4 \%)$ were directly involved in the care of patients with COVID-19. The respondents reported moderate levels of anxiety and feelings of being overloaded with work. The anxiety levels were higher in women than in men. Most of the respondents experienced a feeling of a strong restriction on their private lives and a change in their work routine. The residents also reported a moderate disruption in their training and research activities. In conclusion, early career geriatricians experienced a major impact of COVID-19 on their professional and private lives.
\end{abstract}

Keywords COVID-19 · Survey · Early career geriatricians · Training · Anxiety

\section{Introduction}

The COVID-19 pandemic has brought unprecedented challenges to healthcare workers across the globe [1] evoking feelings of anxiety [2, 3], work overload [3], and a disruption of private lives [4]. The availability of personal protective equipment (PPE) is important in preventing disease transmission; its shortage has been associated with worse outbreaks and the fear of getting infected among medical staff members [5].

Since age is an independent risk factor for having severe cases of COVID-19, hospitalizations, and death [6, 7], this

Vojtech Mezera

wojslaw@seznam.cz; vojtech.mezera@nempk.cz

Extended author information available on the last page of the article pandemic has been having a major impact on older adults [8]. Considering that geriatricians are trained in the care of frail older adults, geriatric medicine should thus be a natural and fitting specialty for older people suffering from COVID19 [9]. The overload with work due to the COVID-19 pandemic, including the multitude of patients' experiencing incurable suffering and death [10], increased the likelihood in experiencing significant impact on both a professional and personal level. Disruptions in postgraduate medical training and research were reported in different medical fields [11, $12]$.

No previous studies have explored the effects of the COVID-19 pandemic on early career geriatricians. Therefore, we aimed to analyze the psychological, social, and educational impact of COVID-19 on early career geriatricians in several European countries. 


\section{Methods}

This was a cross-sectional online survey conducted from February till March 2021 among early career geriatricians throughout Europe. The Early Careers Geriatricians Initiative (ECGI; formerly Young Geriatrician Initiative) [13] was determined to being an ideal medium to run this survey.

Our survey included residents in training or consultants in geriatric medicine with no more than 10 years since becoming consultants. The exclusion criteria were undergraduate students, non-medical healthcare professionals, non-geriatric specialties, and consultants with more than 10 years of experience. The questionnaire (Supplement 1) was translated into 16 different languages. The collected responses were translated back into English.

We processed the data by using Sheets (Google LLC) and Excel (Microsoft Corporation). The Chi-square tests were performed using Prism 9.2.0 (GraphPad Software). The data are given as percentages of the respective groups as well as absolute numbers in the case of frequency data. The continuous variables are shown as median [interquartile (IQ) range]. A $p<0.05$ was set as a threshold of significance.

\section{Results}

We obtained a total of 884 responses. After applying both inclusion and exclusion criteria, we evaluated 721 responses (Fig. 1). Most of the respondents were female $(n=561$, $77.8 \%)$ and residents in geriatric medicine $(n=394$; $54.6 \%)$. The overall majority of the respondents $(n=659$; $91.4 \%$ ) were directly involved in the care of patients with
COVID-19. The demographic characteristics are provided in Table 1. A full set of included responses is provided in Supplement 2.

The respondents reported a moderate level of anxiety and work overload (median of 3, IQ range of 2 for both). We found the female gender as a risk factor compounding both variables $(p<0.05)$. There were $59.2 \%$ of respondents $(n=427)$ who stated that their daily routine has "strongly" or even "very strongly" changed. Looking at the impact on their personal lives, $66.7 \%$ of the respondents $(n=481)$ experienced a strong or very strong disruption of their private lives. Most of the respondents answered that they had good access to diagnosis and treatment policies as well as to PPE (median of 4 and IQ range of 1 for all). The residents in geriatric medicine reported a moderate disruption in training and research (median of 3 and IQ range of 2 for both).

Most $(90.4 \%)$ of the respondents indicated at least one positive consequence of the pandemic. Markedly, $28 \%$ of the respondents found greater recognition of geriatric medicine as a specialty and $18.3 \%$ felt that there was an increased focus on care of older adults (Table 2).

\section{Discussion}

The majority of the early career geriatricians involved in the survey were at the forefront of the care of older adults with COVID-19. The respondents reported a moderate level of anxiety and work overload. In addition, the respondents strongly agreed with having experienced changes in their work routine and restrictions in their private lives. The

Fig. 1 Flowchart of respondents

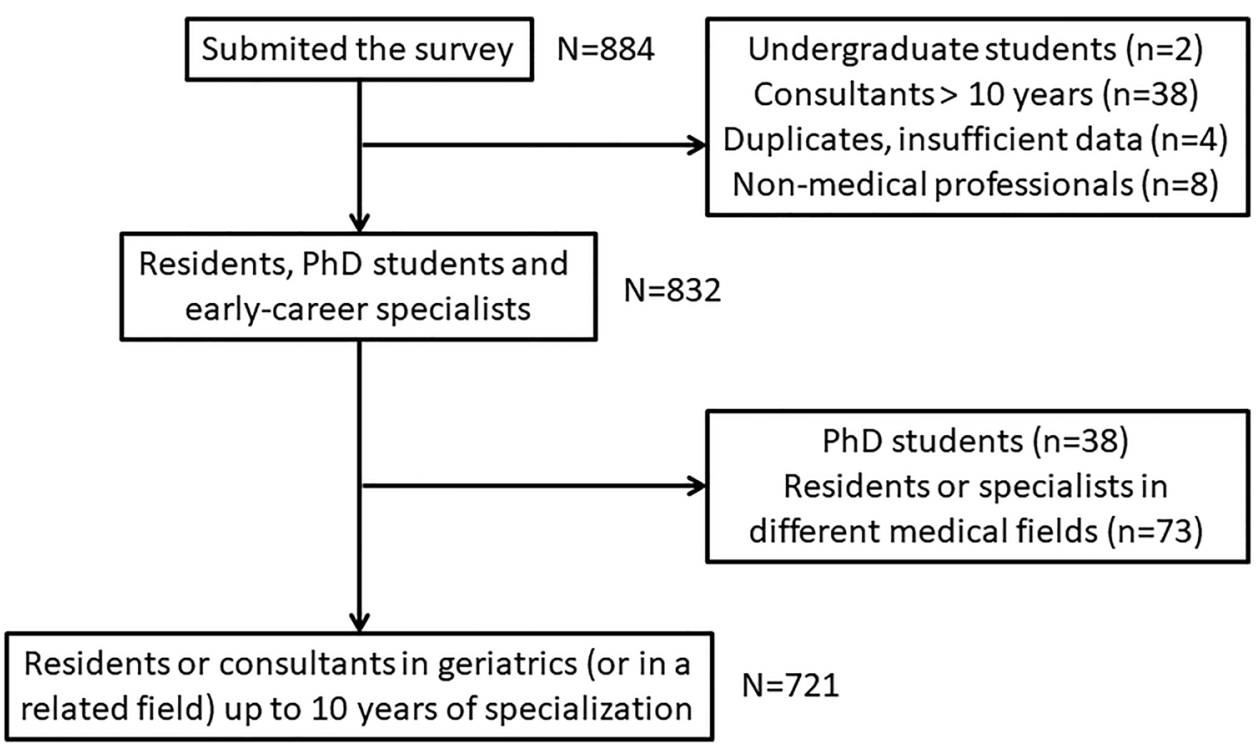


Table 1 Demographic characteristics of the respondents

\begin{tabular}{|c|c|c|}
\hline Parameter & Option & $\%(n)$ \\
\hline \multirow[t]{5}{*}{ Age } & $<25$ years & $3.5(29)$ \\
\hline & $25-29$ years & $18.3(152)$ \\
\hline & $30-34$ years & $30.0(250)$ \\
\hline & $35-39$ years & $21.3(177)$ \\
\hline & $>40$ years & $26.8(223)$ \\
\hline \multirow[t]{3}{*}{ Gender } & Male & $22.1(159)$ \\
\hline & Female & $77.8(561)$ \\
\hline & No answer & $0.1(1)$ \\
\hline \multirow[t]{3}{*}{ Professional group } & Resident in training, geriatric medicine & $54.6(394)$ \\
\hline & Consultant in geriatric medicine & $45.4(327)$ \\
\hline & & Median (IQ range) \\
\hline \multirow[t]{2}{*}{ Years as consultants } & & $3(3)$ \\
\hline & & $\%(n)$ \\
\hline \multirow[t]{5}{*}{ Work site } & University hospital & $50.3(363)$ \\
\hline & Regional hospital & $23.2(167)$ \\
\hline & Local hospital & $18.3(132)$ \\
\hline & Private clinic & $4.2(30)$ \\
\hline & Other facility & $4.0(29)$ \\
\hline \multirow[t]{13}{*}{ Working environment } & Pre-hospital emergency medical care & $2.1(15)$ \\
\hline & Emergency department & $15.8(114)$ \\
\hline & Acute ward (general) & $16.2(117)$ \\
\hline & Acute ward (geriatric) & $60.6(437)$ \\
\hline & Long-term care & $10.5(76)$ \\
\hline & Rehabilitation ward & $10.4(75)$ \\
\hline & Nursing home & $7.5(54)$ \\
\hline & Palliative care & $8.9(64)$ \\
\hline & Geriatric mobile team & $8.2(59)$ \\
\hline & Primary care (family doctor, general practitioner) & $3.3(24)$ \\
\hline & Outpatient clinic & $18.3(132)$ \\
\hline & Other & $4.3(31)$ \\
\hline & & $\%(n)$ \\
\hline \multirow[t]{19}{*}{ Country where the participants are working } & Albania & $0.1(1)$ \\
\hline & Austria & $0.3(2)$ \\
\hline & Belarus & $0.1(1)$ \\
\hline & Belgium & $6.2(45)$ \\
\hline & Croatia & $0.1(1)$ \\
\hline & Czech Republic & $2.9(21)$ \\
\hline & Denmark & $1.2(9)$ \\
\hline & Estonia & $0.4(3)$ \\
\hline & Finland & $2.1(15)$ \\
\hline & France & $11.5(83)$ \\
\hline & Germany & $1.4(10)$ \\
\hline & Greece & $0.1(1)$ \\
\hline & Hungary & $0.3(2)$ \\
\hline & Iceland & $0.1(1)$ \\
\hline & Ireland & $0.7(5)$ \\
\hline & Israel & $0.3(2)$ \\
\hline & Italy & $8.0(58)$ \\
\hline & Latvia & $0.1(1)$ \\
\hline & Lithuania & $1.4(10)$ \\
\hline
\end{tabular}


Table 1 (continued)

\begin{tabular}{|c|c|c|}
\hline Parameter & Option & $\%(n)$ \\
\hline & Malta & $0.7(5)$ \\
\hline & The Netherlands & $4.2(30)$ \\
\hline & North Macedonia & $0.3(2)$ \\
\hline & Norway & $0.7(5)$ \\
\hline & Poland & $1.1(8)$ \\
\hline & Portugal & $0.6(4)$ \\
\hline & Romania & $0.4(3)$ \\
\hline & Russia & $7.4(53)$ \\
\hline & Serbia & $0.1(1)$ \\
\hline & Slovenia & $1.8(13)$ \\
\hline & Spain & $22.3(161)$ \\
\hline & Sweden & $5.1(37)$ \\
\hline & Switzerland & $3.2(23)$ \\
\hline & Turkey & $4.7(34)$ \\
\hline & United Kingdom & $5.0(36)$ \\
\hline & No answer & $4.9(35)$ \\
\hline \multirow[t]{3}{*}{ Directly involved in the care of patients with COVID-19 } & Yes & $91.4(659)$ \\
\hline & No & $8.3(60)$ \\
\hline & Other & $0.3(2)$ \\
\hline \multirow[t]{4}{*}{ Where did the care for patients with COVID-19 take place } & At the regular work site & $65.5(472)$ \\
\hline & Mobilized to other work locations & $8.0(58)$ \\
\hline & Combination of both & $18.0(130)$ \\
\hline & Other or no answer & $8.5(61)$ \\
\hline
\end{tabular}

The frequency data are given as percentages (absolute number). The continuous variables are shown as median value [interquartile (IQ) range]

residents in geriatric medicine reported a moderate disruption in their training and research activities.

As apparent from our survey, most of the early careers geriatricians have been working directly with the patients infected with COVID-19. Care workers directly involved in the medical care of patients with COVID-19 are at a higher risk of experiencing psychological burden [2], [3]. This is in line with our observations that most of our respondents reported having strong changes in their work routines. Additionally, the disruption in their personal lives reported is similar to the observations of other authors [4].

A strength of this study is that the participants came from a large number of countries throughout Europe. Also as far as we know, this is the first survey among early career geriatricians who are involved in the care of frail older adults.
Table 2 Optimistic insights/ benefits of the pandemic

\begin{tabular}{ll}
\hline Option & $\%(n)$ \\
\hline Nothing good came out of it & $7.6(55)$ \\
The abundance of free online educational material & $35.5(256)$ \\
Easy access to the EuGMS E-Congress 2020 & $19.0(137)$ \\
The fast development of telemedicine & $41.6(300)$ \\
A wave of solidarity & $29.7(214)$ \\
A new feeling of appreciation and/or respect toward healthcare workers & $21.8(157)$ \\
An opportunity to learn something new & $43.6(314)$ \\
An opportunity to work alongside health care professionals of other specialties & $41.3(298)$ \\
The impression that there was an increased focus on the care of older people & $18.3(132)$ \\
I found that the specialty of geriatric medicine was further recognized by other medical spe- & $28.0(202)$ \\
cialties & \\
Others, please specify & $6.2(45)$ \\
\hline
\end{tabular}


However, there were some limitations to our study. First, we did not use validated scales or instruments. Second, there was an uneven representation of countries with Spain representing over $20 \%$ of the respondents and some countries having only a small number of respondents. Third, responses reflected the subjective feelings of the respondents [2] and might not exactly reflect the objective situation (e.g., in case of PPE shortage). Fourth, there might have been a selection bias, i.e., only people having strong (especially negative) experience having filled in the survey.

Many early career geriatricians throughout Europe were among the frontline workers in the care of COVID-19. This has led to disruptions in their private lives as well as changes in their work routines, but also caused moderate levels of anxiety and a feeling of being overloaded with work. Interestingly, a vast majority of respondents were able to find at least one positive consequence of the pandemic. A positive result of the pandemic was that for almost $30 \%$ of the respondents, the field of geriatrics has gained more respect and recognition among other medical specialities.

Supplementary Information The online version contains supplementary material available at https://doi.org/10.1007/s41999-021-00605-1.

Acknowledgements We would like to thank the following friends and colleagues who translated the questionnaire into their native languages: Yasin Erarlsan, Rosalba Perrone, Ksenia Cherezova, Vita Klimašauskienè, Sara Vale, Sara Miranda, Jozef Banik, Dominika Stratilkova, Mikael Magnano, Joanna Zemiańska, Martin Borch Jensen, Vera Secova, and Uliana Pryjmycz. We would like to thank Dr. Cyrus Rasti, MD, for the English language correction of the manuscript.

Funding This study was not supported by any funding.

Data availability It is available in the supplemental material's section.

Code availability Not applicable.

\section{Declarations}

Conflict of interest On behalf of all authors, the corresponding author states that there is no conflict of interest.

Ethics approval Not applicable.

Consent to participate The respondents agreed to have their responses processed in an anonymous fashion by filling and submitting the questionnaire.

Consent for publication All authors have given their consent for publication.

\section{References}

1. Bahadirli S, Sagaltici E (2021) Post-traumatic stress disorder in healthcare workers of emergency departments during the pandemic: a cross-sectional study. Am J Emerg Med 50:251-255. https://doi.org/10.1016/j.ajem.2021.08.027

2. Paffenholz P, Peine A, Hellmich M, Paffenholz SV, Martin L, Luedde M et al (2020) Perception of the 2020 SARS-CoV-2 pandemic among medical professionals in Germany: results from a nationwide online survey. Emerg Microbes Infect 9:1590-1599. https://doi.org/10.1080/22221751.2020.1785951

3. Lai J, Ma S, Wang Y, Cai Z, Hu J, Wei N et al (2020) Factors associated with mental health outcomes among health care workers exposed to coronavirus disease 2019. JAMA Netw Open 3:e203976. https://doi.org/10.1001/jamanetworkopen.2020.3976

4. Venkataram T, Goyal N, Dash C, Chandra PP, Chaturvedi J, Raheja A et al (2020) Impact of the COVID-19 pandemic on neurosurgical practice in india: results of an anonymized national survey. Neurol India 68:595-602. https://doi.org/10.4103/00283886.289004

5. McGarry BE, Grabowski DC, Barnett ML (2020) Severe staffing and personal protective equipment shortages faced by nursing homes during the COVID-19 pandemic. Health Aff (Millwood) 39:1812-1821. https://doi.org/10.1377/hlthaff.2020.01269

6. Rosenthal N, Cao Z, Gundrum J, Sianis J, Safo S (2020) Risk factors associated with in-hospital mortality in a US national sample of patients with COVID-19. JAMA Netw Open 3:e2029058e2029058. https://doi.org/10.1001/jamanetworkopen.2020.29058

7. Levin AT, Hanage WP, Owusu-Boaitey N, Cochran KB, Walsh SP, Meyerowitz-Katz G (2020) Assessing the age specificity of infection fatality rates for COVID-19: systematic review, meta-analysis, and public policy implications. Eur J Epidemiol 35:1123-1138. https://doi.org/10.1007/s10654-020-00698-1

8. Hashan MR, Smoll N, King C, Ockenden-Muldoon H, Walker J, Wattiaux A et al (2021) Epidemiology and clinical features of COVID-19 outbreaks in aged care facilities: A systematic review and meta-analysis. EClinicalMedicine 33:100771. https://doi.org/ 10.1016/j.eclinm.2021.100771

9. O'Hanlon S, Dhesi J, Aronson L, Inouye SK (2021) Covid-19: a call for mobilizing geriatric expertise. Eur Geriatr Med 12:597600. https://doi.org/10.1007/s41999-021-00500-9

10. Beyens MMJ, Verelst FR, Moorkens G, Twickler MT (2020) Trials and tribulations of young residents fighting COVID-19. Eur J Clin Invest 50:e13336. https://doi.org/10.1111/eci.13336

11. Abati E, Costamagna G (2020) Education research: effect of the COVID-19 pandemic on neurology trainees in Italy: a residentdriven survey. Neurology 95:1061-1066. https://doi.org/10.1212/ WNL.0000000000010878

12. Megaloikonomos PD, Thaler M, Igoumenou VG, Bonanzinga T, Ostojic M, Couto AF et al (2020) Impact of the COVID19 pandemic on orthopaedic and trauma surgery training in Europe. Int Orthop 44:1611-1619. https://doi.org/10.1007/ s00264-020-04742-3

13. Ekdahl AW (2021) ECGI-early careers geriatricians initiative 2020. https://www.eugms.org/about-us/early-careers-geriatrici ans-initiative.html. Accessed 14 Aug 2021

Publisher's Note Springer Nature remains neutral with regard to jurisdictional claims in published maps and institutional affiliations. 


\section{Affiliations}

Vojtech Mezera ${ }^{1,2}$ (D) Anne W. Ekdahl ${ }^{3} \cdot$ Dominic Bertschi $^{4} \cdot$ Maria Bonnici $^{5,6,7} \cdot$ Rui Buzaco $^{8}$. Santiago Cotobal Rodeles ${ }^{9} \cdot K$ seniia Eruslanova ${ }^{10} \cdot$ Lubov Matchekhina $^{10} \cdot$ Laura Monica Perez Bazan $^{11}$. Itxaso Marin Epelde ${ }^{12} \cdot$ Marina Kotsani $^{13}$ - Grazia Daniela Femminella ${ }^{14} \cdot$ Meltem Koca $^{15} \cdot$ Marian Dejaeger $^{16,17}$

1 Geriatric Center, Pardubice Hospital, Kyjevska 44, 53203 Pardubice, Czech Republic

2 3rd Department of Internal Medicine-Metabolism and Gerontology, University Hospital Hradec Králové, Charles University, Faculty of Medicine in Hradec Králové, Hradec Králové, Czech Republic

3 Department of Clinical Sciences, Lund University, Lund, Sweden

4 Department of Geriatrics, Inselspital, Bern University Hospital, University of Bern, 3010 Bern, Switzerland

5 Department of Geriatric Medicine, University of Malta, Msida, Malta

6 Karin Grech Hospital, Pietà, Malta

7 St Vincent De Paul Residence, Luqa, Malta

8 Unidade de Saúde Familiar Novo Mirante, ACES Loures Odivelas, Lisbon, Portugal

9 Geriatría Hopital Universitario Severo Ochoa, Leganes, Madrid, Spain
10 Russian Gerontology Research Centre, Pirogov Russian National Research University, Moscow, Russia

11 RE-FIT Barcelona Research Group, Parc Sanitari Pere Virgili, Vall d'Hebron Institute of Research (VHIR), Barcelona, Spain

12 Complejo Hospitalario de Navarra, Pamplona, Spain

13 Department of Geriatrics, CHRU de Nancy, 54500 Vandœuvre-lès-Nanc, France

14 Department of Translational Medical Sciences, University of Naples Federico II, Naples, Italy

15 Division of Geriatrics, Department of Internal Medicine, Hacettepe University, Ankara, Turkey

16 Laboratory of Gerontology and Geriatrics, Department of Public Health and Primary Care, KU Leuven, Leuven, Belgium

17 Department of Geriatrics, University Hospitals Leuven, Leuven, Belgium 